TAO, Vol. 15, No. 3, 523-543, September 2004

\title{
Application of Space-borne Radar Interferometry on Crustal Deformations in Taiwan: A Perspective from the Nature of Events
}

\author{
Chung-Pai Chang ${ }^{1, *}$, Kun-Shan Chen ${ }^{1}$, Chin-Tien Wang ${ }^{1}$, Jiun-Yee Yen ${ }^{1}$, \\ Tsui-Yu Chang ${ }^{2}$ and Chi-Wen Lin $^{3}$
}

(Manuscript received 19 April 2004, in final form 28 June 2004)

\begin{abstract}
The orogen of Taiwan is young and active as indicated by the elevation of its topography and dense seismicity. Ongoing crustal deformations therefore cause considerable damage. Taiwan's high population density means that mitigation of geological hazards has become an urgent task. This paper reviews our recent results using the radar interferometry technique to study crustal deformation in Taiwan. In order to better describe our approach and the limitations of this technique, we have classified crustal deformation into intense and gentle events reflecting different deformation styles. Five case studies of deformation events using DInSAR images have been reported. They are: the coseismic deformation of the Chi-Chi earthquake, uplift of the Tainan area, active deformation of the Hukuo area, rapid land-subsidence in the Chungli area, and seasonal-varied landsubsidence in the Pingtung area. Our results show that this technique is worth developing for future study of neo-tectonic activity and environmental change.
\end{abstract}

(Key words: Radar interferometry, Crustal deformation, Taiwan)

\section{INTRODUCTION}

Monitoring active change in landscapes has become a very important branch of science. Considerable effort has been expanded on understanding the nature of deformations and cor-

\footnotetext{
${ }^{1}$ Center for Space and Remote Sensing Research, National Central University, Chung-Li, Taiwan, ROC

2 Department of Geosciences, National Central University, Chung-Li, Taiwan, ROC

${ }^{3}$ Central Geological Survey, MOEA, Chungho, Taiwan, ROC

* Corresponding author address: Prof. Chung-Pai Chang, Center for Space and Remote Sensing Research, National Central University, Chung-Li, Taiwan, ROC; E-mail: cpchang@csrsr.ncu.edu.tw
} 
responding factors. In terms of natural hazard mitigation, tectonically active regions experience abundant risk events, such as landslides, land subsidence, and earthquakes; Taiwan Island is actually an excellent place to observe examples of sustained geologically disastrous processes.

Taiwan Island has experienced more than 10 disastrous earthquakes over the past century (Tsai 1986). It is located between the southeastern periphery of the Eurasian plate and westernmost corner of the Philippine Sea plate and links two subduction systems of opposite subduction polarities, i.e., the Ryukyu subduction system to the northeast and the Manila subduction system to the south-southwest (Chai 1972; Biq 1973; Bowin et al. 1978). Taiwan marks the site of an ongoing oblique collision between the Luzon island arc and the Chinese passive continental margin, with the island of Taiwan formed as an overgrown accretionary wedge (Barrier and Angelier 1986; Suppe 1984; Teng 1990). Based on geodetic studies, this collision is very active (Yu et al. 1997). The rate of deformation that Taiwan is undergoing is high caused by extreme tectonic forces (Chang et al. 2003), and thus the island is threatened with large geological hazard potential.

Since Taiwan also ranks as the second most populated area in the world $\left(639\right.$ persons km$\left.{ }^{-2}\right)$, environmental issues and natural hazard mitigation have become very urgent tasks for its inhabitants. The most efficient method of assisting in hazard mitigation is to monitor areas where the risk potential is highest. This paper reviews some surface deformation events in Taiwan that have been determined by means of the radar interferometry technique.

Radar interferometry is a technique for extracting information on landscape changes on the Earth's surface using the phase content of a radar signal (e.g., Zebker et al. 1994; Massonnet and Feigl 1998). This technique calculates the interference pattern caused by the difference in phase between two space-borne radar images acquired at two distinct times (Fig. 1). Through the use of microwave frequency, the C-band radar images can be utilized as a geodetic tool with unsurpassed spatial sampling density $\left(\sim 100\right.$ pixels $\left.\mathrm{km}^{-2}\right)$, competitive precision $(\sim 1 \mathrm{~cm})$, and useful observation cadence $\left(1\right.$ pass month $\left.^{-1}\right)$. These images are thus considered capable of detecting obscure deformation occurrences in the plains area of Taiwan.

Since interferometry techniques for monitoring crustal deformations are only valid when using SAR (Synthetic Aperture Radar) images, availability of SAR images limits how far back in time this technique works. The SAR images used in this paper were acquired by ERS1 and ERS2, two satellites launched by the European Space Agency, and the available data dates back to 1993 (launch time of the ERS1 satellite). These images allow us to monitor crustal deformation events that are both recent and active.

\section{NATURE OF CRUSTAL DEFORMATIONS}

Crustal deformations can be divided into two major categories based on duration of events and measures of ground offset, these being intense deformation and gentle deformation. There are various limitations when applying the radar interferometry technique to events of different type, details of which will be discussed in the following text.

An intense event is defined as an incident of crustal deformation that yields a relatively 


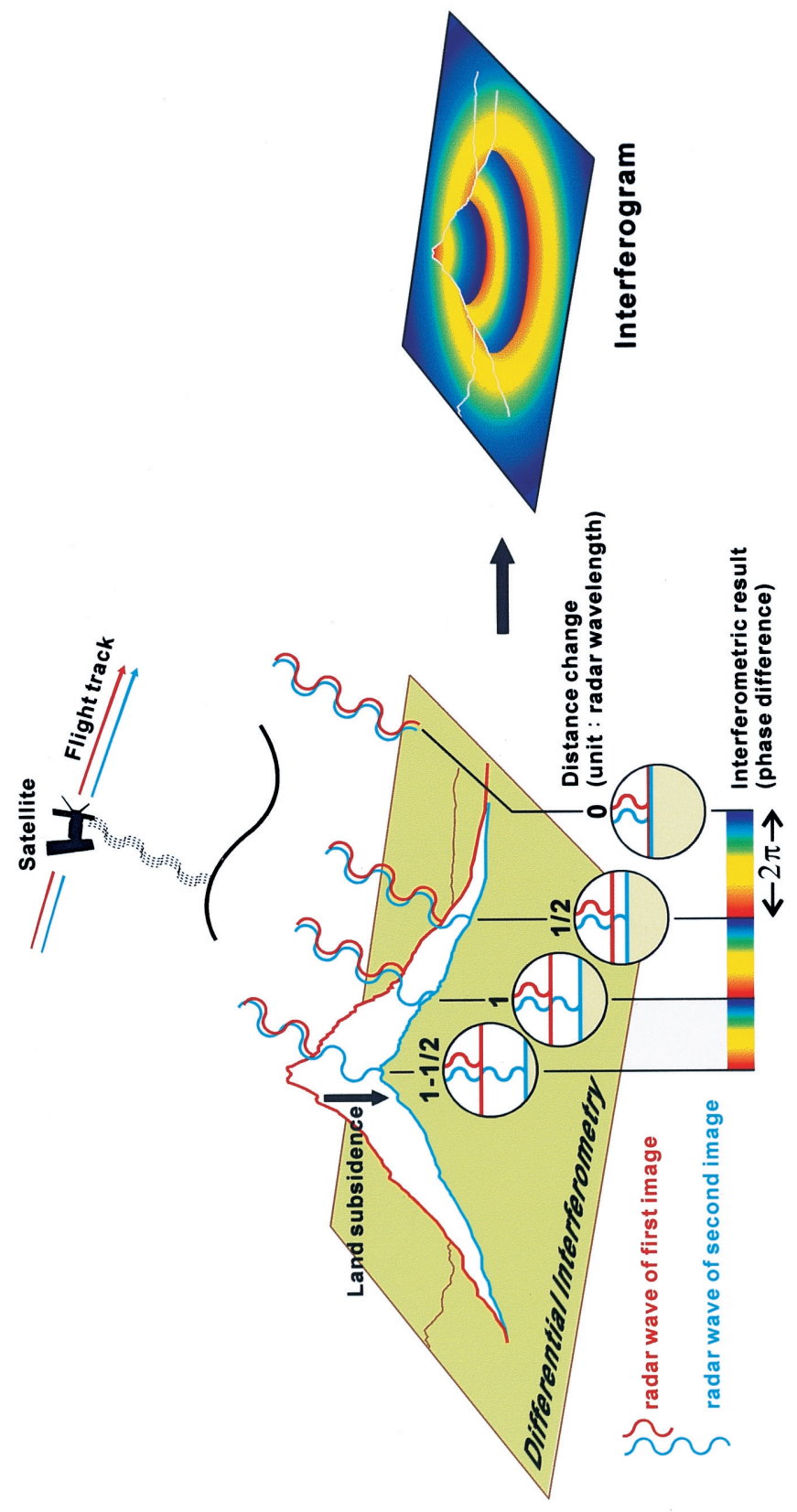

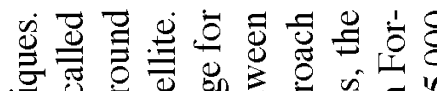

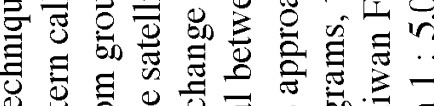
记

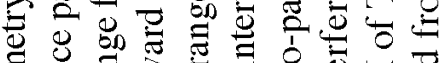

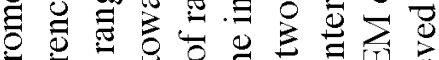

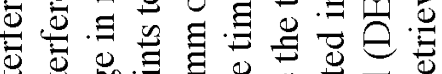

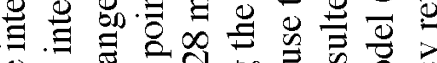

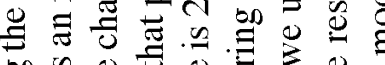
of

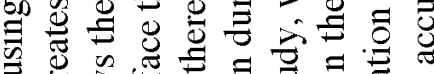

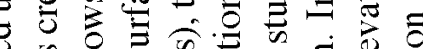

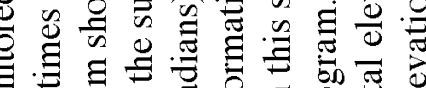

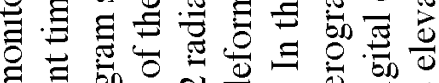
政

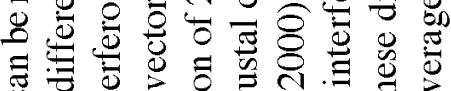

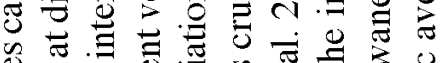

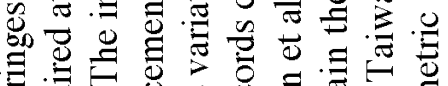

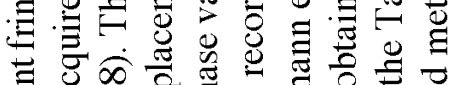

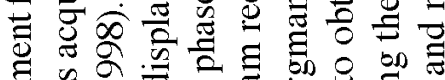
政

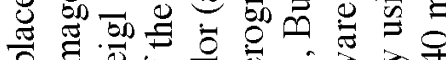

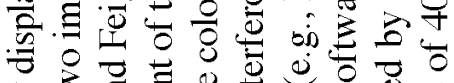

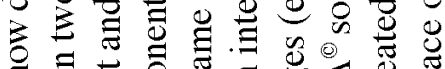
的欧

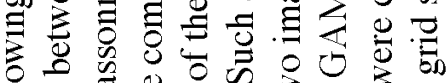

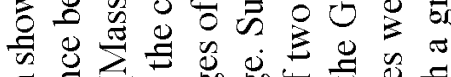

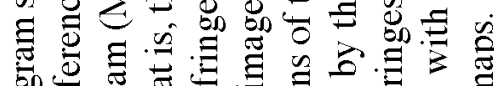

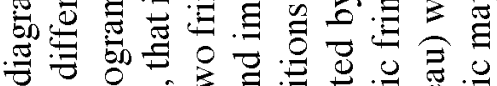

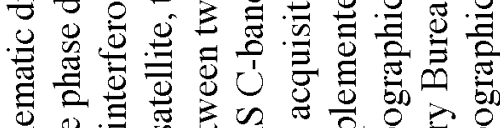

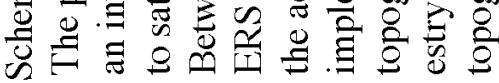

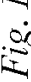


large deformation within a short time. For example, a strong, shallow earthquake that causes a large surface rupture along a fault line. The offset encountered along both sides of a rupture of this nature is often large; however, the recurrence interval is typically long. Many large earthquakes have been studied using radar interferometry technique; for instance, the Landers earthquake in California (Massonnet et al. 1993) and the Chi-Chi earthquake in Taiwan (Pathier et al. 2003; Chang et al. 2004a). Co-seismic deformation patterns were clearly revealed by the interferograms generated from image pairs immediately before and after the main shocks. Generally, the results from those studies are accurate and clear.

The second type of event is termed a gentle event, which does not have a single catastrophic incident but occurs over a longer time span, analogous to a series continuous small incidents. One example of a gentle event is surface subsidence caused by excess pumping of groundwater in the Linbien area of southern Taiwan. The subsidence rate is too subtle to be noticed on our human sensory scale yet it has occurred rapidly enough over the past 20 years that houses in the area have sunk a full floor. Since the deformation rate is small conducting interferometry analysis requires very precise parameters and image calibration. The quality of the results becomes very sensitive to other factors that could alter the characteristics of radar waves such as deviations in satellite orbits, atmospheric disturbances, topographic relief, etc.

A brief classification of event nature is shown in Table 1. The causes of gentle events include tectonic processes and human activity. These two effects may occur concurrently or compound each other creating a complex deformation pattern and making it difficult to attribute degrees of effect to each factor. This classification scheme enables us to discriminate between styles of crustal deformation and further constrains the uncertainties of radar interferometry technique applied to crustal deformation. In the next paragraph, we will present how we applied the technique to a variety of cases of different nature as shown in Fig. 2.

Table 1. Crustal deformation events of different nature discussed in this paper.

\begin{tabular}{llll}
\hline Nature of event & $\begin{array}{l}\text { Intense } \\
\text { (section 3.1) }\end{array}$ & $\begin{array}{l}\text { Gentle } \\
\text { (section 3.2.a) }\end{array}$ & $\begin{array}{l}\text { Gentle } \\
\text { (section 3.2.b) }\end{array}$ \\
\hline Cause of event & tectonic activity & tectonic activity & Human activity \\
\hline Time scale of each event & days & Months $\sim$ years & Months $\sim$ years \\
\hline Motion per incident & $\begin{array}{l}\text { centimeters } \sim \text { hundreds } \\
\text { of centimenters }\end{array}$ & sub-centimeter & sub-centimeter \\
\hline Recurring frequency & Year $\sim$ hundreds of years & daily (continuing) & daily (continuing) \\
\hline Detectibility & easy & difficult & difficult \\
\hline Example & Chichi coseismic & Tainan and & Chungli and \\
& deformation & Hukou areas & Pingtung areas \\
\hline
\end{tabular}




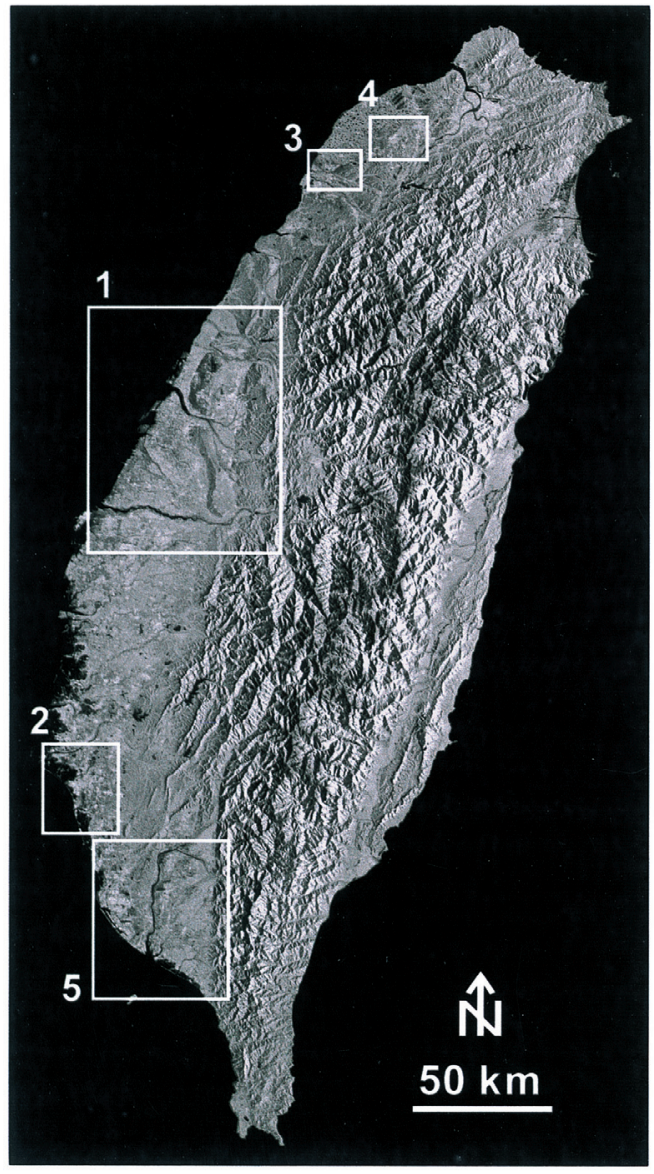

Fig. 2. Studied areas (white rectangular frame) in this paper. 1: Chi-Chi earthquake area (section 3.1). 2: Tainan area (section 3.2.a). 3: Hukou area (section 3.2.a). 4: Chungli area (section 3.2.b). 5: Pingtung area (3.2.b). Background is the stacked radar image of Taiwan acquired by RADARSAT in the last three years.

\section{INTERFEROMETRIC RESULTS}

\subsection{Intense Event - the Chi-Chi Earthquake}

The Chi-Chi earthquake ( $M_{w}$ 7.6), which struck central Taiwan on September 20, 1999 (UTC), caused heavy casualties and widespread damage in Taiwan. It has been recognized as one of the most significant earthquakes in the study of earthquake mechanics thanks to the unprecedented amount of high-quality near-field data it generated (e.g., Teng et al. 2001). 
Integrated GPS measurements showed that major co-seismic displacement and crustal deformation occurred at the hanging wall of the Chelungpu fault (Yu et al. 2001). On the western side of the fault, the footwall area showed relatively little deformation (e.g., Ma et al. 2000; Lee et al. 2001; Rubin et al. 2001; Yu et al. 2001), and the characteristics of surface movement in the footwall area were relatively poorly understood. On the other hand, the westward propagation of the deformation front in Taiwan (Suppe 1981) is probably incubating a future large thrust earthquake in the footwall area of the Chelungpu fault and it warrants a high earthquake potential in terms of risk mitigation.

The interferogram shown in Fig. 3a is selected to involve the time event of the Chi-Chi earthquake. In spite of our careful image selection, radar correlation in the hanging-wall area of Chelungpu fault still breaks down. However, image coherence is good for the footwall area, which exhibits a relatively flat topography and dense inhabitancy. Concentric fringe patterns are clearly shown in the footwall area in Fig. 3a; these fringes possibly indicate the co-seismic displacement of this area. In terms of the round trip distance change between the radar antenna and the ground, the interferometric fringe pattern represents a relative shortening, which increases from the west coast toward the central segment of the Chelungpu fault.

There may be two major causes attributable to the poor interferometric result in the hanging wall of the Chelungpu fault. The first comes from dense vegetation east of the Chelungpu fault. Forest and fruit trees cover hills and mountains in this area, so that it is more difficult to

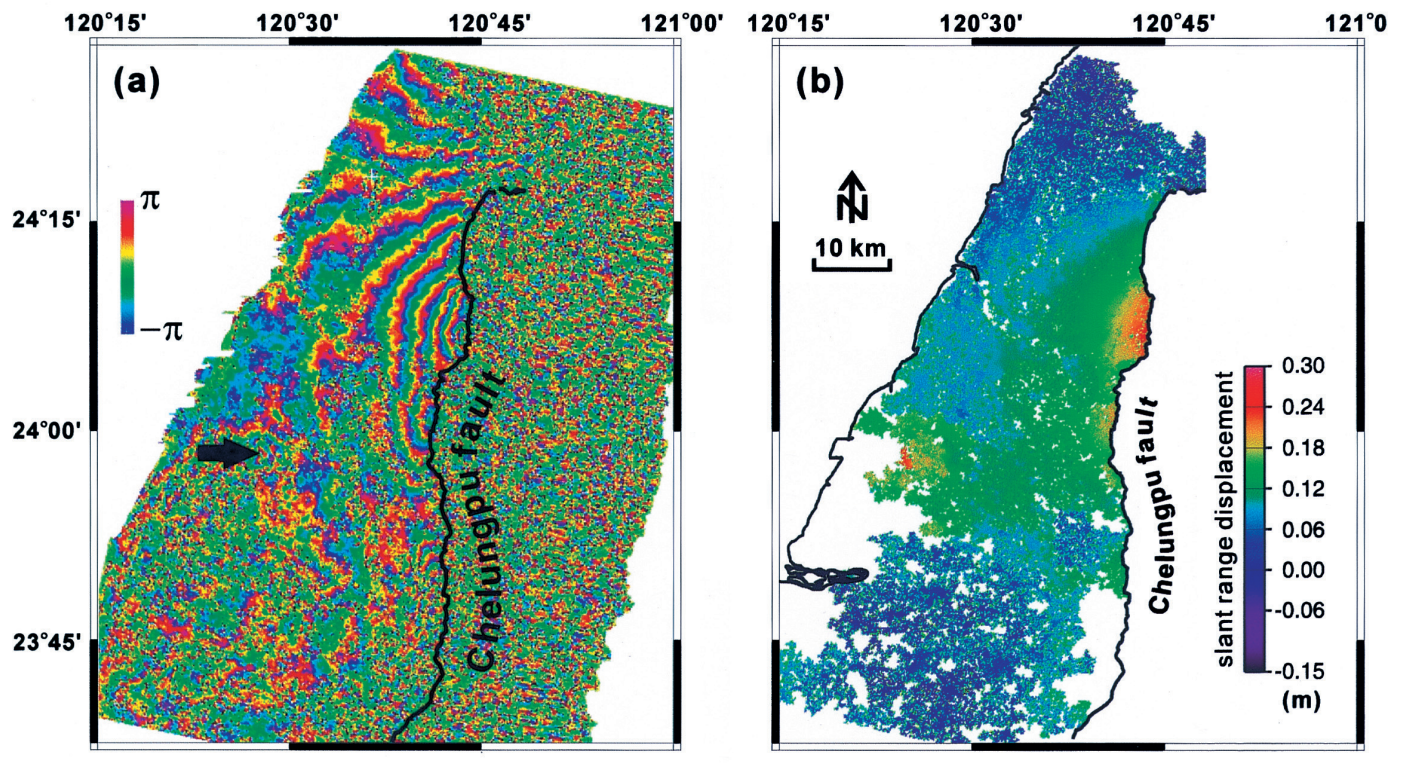

Fig. 3. (a) Interferogram of the central Taiwan area (1999/5/6 1999/10/28; year/month/day). (b) Unwrapped result of interferogram. The amount of displacement is evaluated in slant range direction. 
detect possible displacement by means of the C-band SAR. The second is that the co-seismic displacement of the hanging-wall area might be too large (about $5 \mathrm{~m}$ in general after previous field studies, e.g., Lee et al. 2001; Rubin et al. 2001). Since the C-band SAR is calibrated for detecting surface offset on a scale of centimeters, the interferometric fringes will be overdrawn making it unable to distinguish a large vertical displacement occurring in a narrow area.

Subsequently, we estimate the amount of surface deformation using a phase unwrapping operation. Because interferograms record only relative changes in phase, we cannot identify the fringe corresponding to no deformed area in the interferogram. However, with the advantage of a dense GPS network in the area investigated, we can add a reasonable offset to all the pixels in our co-seismic interferograms in the unwrapping operation. The unwrapped interferogram is shown in Fig. 3b. Maximum shortening in our unwrapped InSAR result is about $26 \mathrm{~cm}$, which occurs around the central segment of the Chelungpu fault.

The simulation of an unwrapped interferogram from GPS data can be applied to control possible orbit error in interferometric results (e.g., Hudnut et al. 1994; Burgmann et al. 2002; Delouis et al. 2002; Donnellan et al. 2002; Feigl et al. 2002). The campaign-surveyed GPS data (data after Yu et al. 2001) used in this study were collected from several campaigns mainly conducted by (1) the Central Geological Survey, Ministry of Economic Affairs, (2) the Satellite Survey Division and Land Survey Bureau, Ministry of Interior, and (3) the Institute of Earth Sciences, Academia Sinica. The GPS measurements were collected within $2 \sim 32$ months before and 3 months after the mainshock of Chi-Chi earthquake, respectively.

We project GPS co-seismic measurements into the slant range direction of a satellite. Thereafter a composite map of the entire study area is constructed using the continuous curvature algorithm, which can prevent undesired oscillation and false local maxima and minima when interpolating scattered data into grids (Smith and Wessel 1990). Figure 4 presents the synthetic slant range displacement derived from the scattered GPS measurements.

At the first approximation, we find that the synthetic result (Fig. 4) shows a very similar fringe pattern in comparison with the real interferogram (Fig. 3b). Actually, the altitude of ambiguity of the image pair used in this study is very good (about $1570 \mathrm{~m}$ ), orbit error and the topographic effect for this study ought be very small and can therefore be neglected. In general, albeit some uncertainties may still remain within the interferometric results, ground displacement determined by our InSAR study is reliable in terms of providing information regarding deformation due to this intense event.

\subsection{Gentle Event}

\section{2.a Tectonic Activity}

Tainan area:

The Tainan tableland surrounds Tainan city in southern Taiwan (geographical location see Fig. 2). This tableland is elongated in shape and is approximately $5 \mathrm{~km}$ long in an east-west direction and $15 \mathrm{~km}$ long in a north-south direction. Its maximum altitude is $30 \mathrm{~m}$ above sea level. The topography of the Tainan tableland shows an east-west asymmetry, dipping gently 


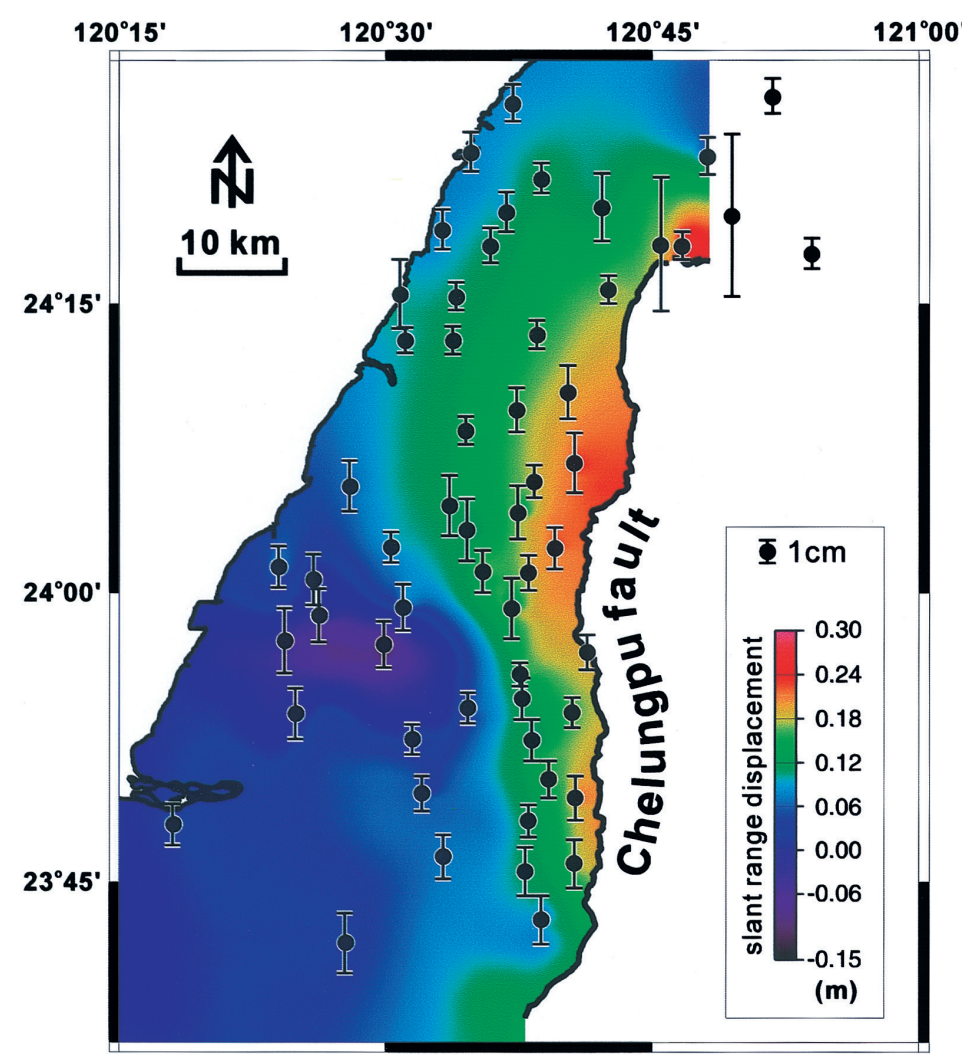

Fig. 4. Near-field co-seismic slant range displacement estimated from GPS measurements. Error bar (95\% confidence) in slant range has been added on each station (data after Yu et al. 2001). Note that the color code is the same as Fig. 3b.

westward to the west, while the eastern part is steeper. The eastern scarp of the Tainan tableland is generally thought to be an active fault (named as Houjiali fault; Sun 1964; Chang et al. 1998).

The western flank of the Tainan tableland is densely populated and urban development in recent years has expanded eastward closer to the Houjiali fault. If the Houjiali fault proves active, such a tectonic scarp probably represents a segment of the west-propagating deformation front of western Taiwan. Another issue associated with the Houjiali fault is whether it significantly raises the level of seismic hazard in the Tainan metropolitan area. Interferometry study can provide more information regarding the questions mentioned above.

The Tainan tableland has a peculiar deformation pattern different from neighboring areas. 
The amount of slant range displacement resolved from all six image pairs indicates that deformation on the western side of the Houjiali fault is significantly larger than on the eastern side (Figs. 5 and 6a). The cumulative slant range displacement along profile AA' shows an offset of about $4 \mathrm{~cm}$ in 4 years (from 1997 to 2000) (Fig. 6b). The displacement rates derived from each image pair are shown in Fig. $6 \mathrm{c}$ and are mostly hovering around $1 \mathrm{~cm} / \mathrm{yr}$ except the time frame of pair-6 (around year 2000), which has a higher rate almost reaching $2 \mathrm{~cm}$ per year. Furthermore, the displacement pattern of pair- 6 is significantly different from other pairs; the western side of the tableland shows a sharp displacement, whereas the displacement on its eastern side exhibits a small amount. It shows an inverse movement in crustal deformation between pair 6 and the other pairs, in such pairs the tableland shows westward tilting. To answer whether or not this reverse tilting was induced by the 1999 Chi-Chi earthquake, we need further monitoring and research in the Tainan area. Also to answer what are the underlying structures that control its deformation style we need to explore more subsurface geology.

More practically, a fast deformation rate in this area has delivered a strong message in that uneven deformation across the tableland and an abrupt rate drop across the Houjiali fault could cause damage to buildings and other infrastructures even without a substantial earthquake event. It is therefore worth considering active deformation in the Houjiali fault when future urban planning occurs.
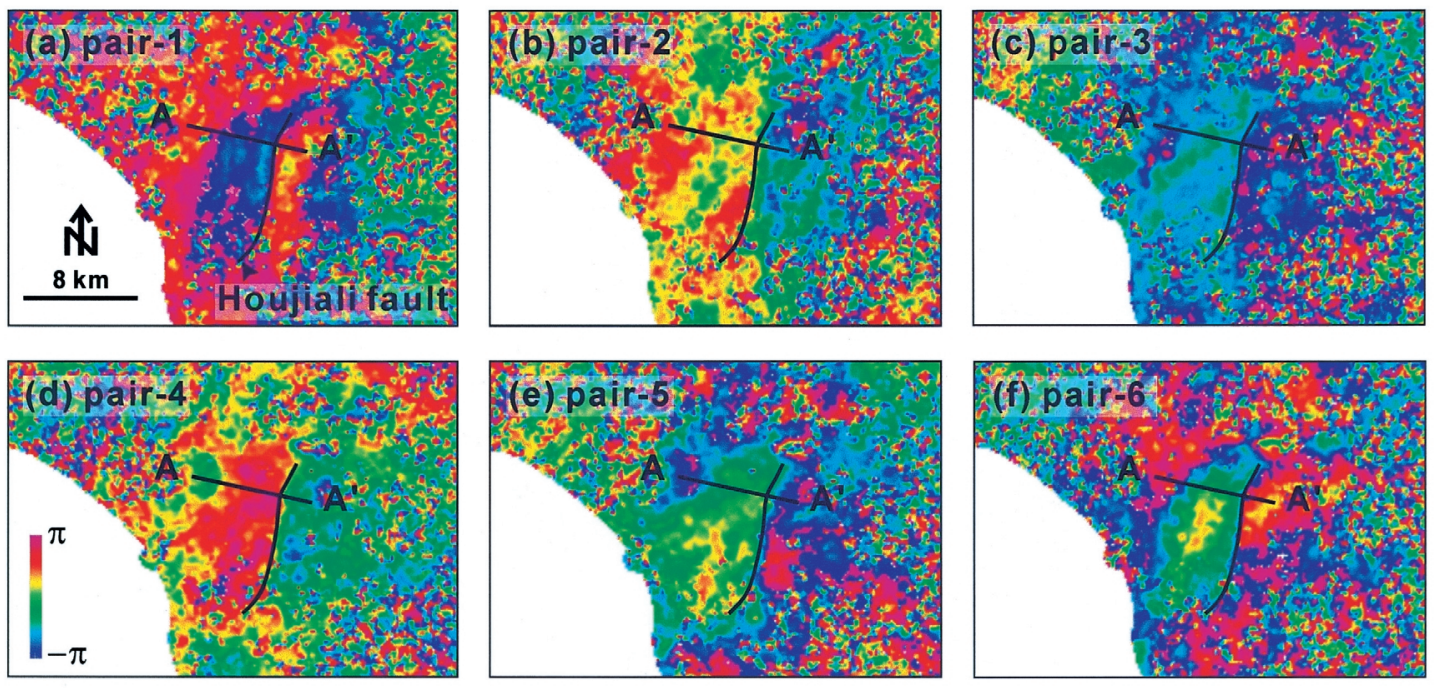

Fig. 5. Interferograms of the Tainan area. (a) Pair-1: 1997/2/20 1998/2/5 (year/ month/day); (b) Pair-2: 1998/1/1 1998/11/12; (c) Pair-3: 1998/1/1 1999/1/21; (d) Pair-4: 1998/11/12 2000/1/6; (e) Pair-5: 1999/1/21 2000/1/6; (f) Pair-6: 2000/1/6 2000/11/16. 
(a) slant range displacement

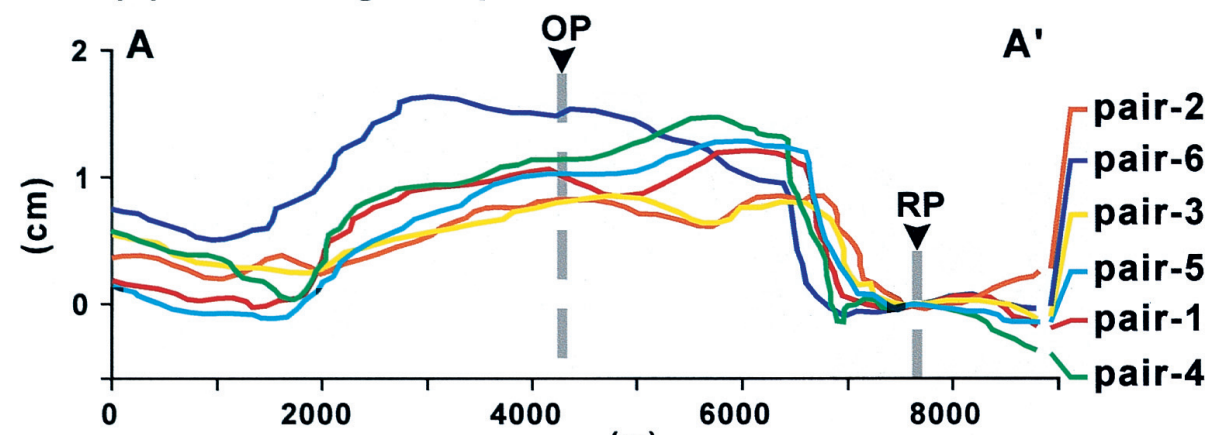

(m)
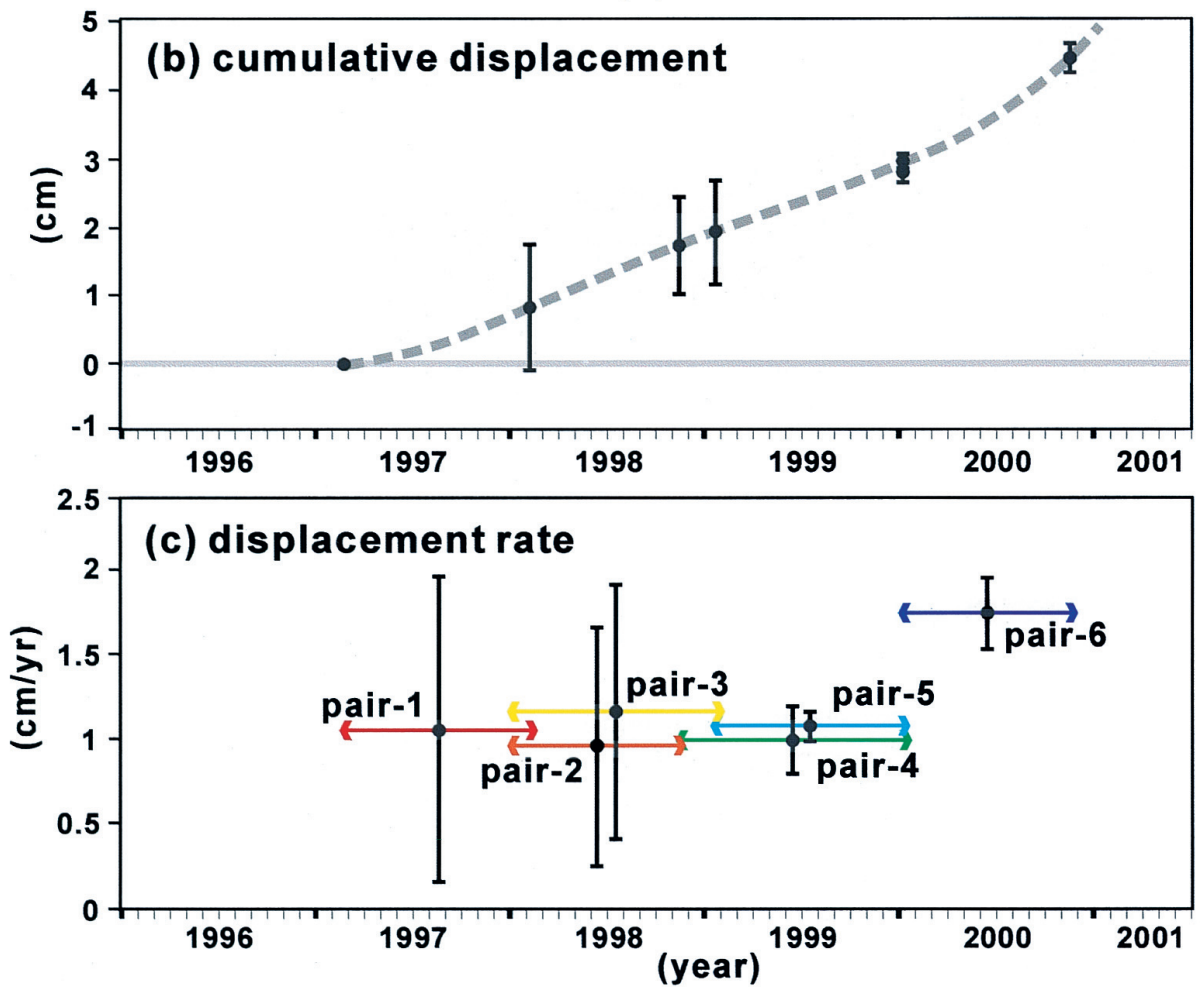

Fig. 6. (a) Slant range displacement along the profile AA' in Fig. 5. OP: observing point; RP: reference point. (b) Estimated cumulative displacement between $\mathbf{O P}$ and RP in Fig. 6a. Error bar is estimated from the ratio of the topographic altitude $(h t)$ to the altitude of ambiguity ( $h a \simeq 9416$ / vertical baseline offset) $($ error $=$ wave length $* h t / h a)$. (c) Displacement rate between the $\mathbf{O P}$ and $\mathbf{R P}$ of each image pair in Fig. 6 a. 
Hukou area:

The Hukou fault (also called as the Yangmei fault), situated at the boundary between Taoyuan and the Hsinchu counties, is the most important east-west striking structure in the northwestern Taiwan. The linear scarp of this fault is clear; however, no outcrop has been found along this lineament. The existence of this fault and whether the fault is active has been in debate (e.g., Chang et al. 1998). After considering stratigraphic features, some geologists believed that the regional deformation may be controlled by an active fold - the Hukou anticline (e.g., Tang 1963). The use of radar interferometry technique in this case is an opportunity to monitor crustal deformation and help decipher structures in the area.

Six image pairs of successive time frames, spanning from 1993 to 2003, have been chosen to produce the interferograms for the area of interest (Fig. 7). The results of slant range displacement along the profile AA' from different image pairs were stacked together with a reference point (reference's location see Fig. 8a). Change in the observation point relative to the reference point is shown in Fig. 8b.

The interferograms produced clearly show deformation immediately south of the Hukou fault in the area of interest. The semi-circular deformation zone is truncated by the Hukou fault at its northern part and forms an open-circular pattern in all the interferograms. This undoubtedly indicates a difference in deformation patterns in neighboring areas separated by the Hukou fault and suggests the existence of an active fault (or an active related fold), which has been uplifted more than $6 \mathrm{~cm}$ over the past 12 years. The relative uplift rate of the area is around $0.5 \mathrm{~cm} \mathrm{yr}^{-1}$ for the period 1996 to 1999 and was approximately $1 \mathrm{~cm} \mathrm{yr}^{-1}$ before 1996 and after 1999 (Fig. 8c).

The slant range displacement along profile AA' points to an interesting style of deformation. In the study area, the more southern side of the hanging wall (the southern block) is being uplifted faster than the front of the hanging wall. The rate increase from $0.5 \mathrm{~cm} \mathrm{yr}^{-1}$ to $1 \mathrm{~cm} \mathrm{yr}^{-1} \mathrm{by}_{\text {the }}$ end of 1999 might not be a coincidence but related to the occurrence of the Chi-Chi earthquake. Such a significant change in deformation pattern or rate before and after the Chi-Chi earthquake seems to be observable in many places in Taiwan.

\section{2.b Human Activity}

Chungli area:

The crustal deformation caused by human activity is generally very local, unsteady, and cannot be explained by regional tectonic regimes or local structural geology. Since these deformations are mostly temporal, of which the deformation rate and style may change very rapidly. All these make the measurement of surface deformation a difficult task. Moreover, human activity is concentrated in urban areas, where cover and shadows from buildings raise errors in GPS observations. The radar interferometry technique can overcome these difficulties and provide useful information.

It has been reported that centimeter-scale land subsidence have occurred in some areas of Taoyuan County in northern Taiwan, which may have been induced by human activity (Chang 

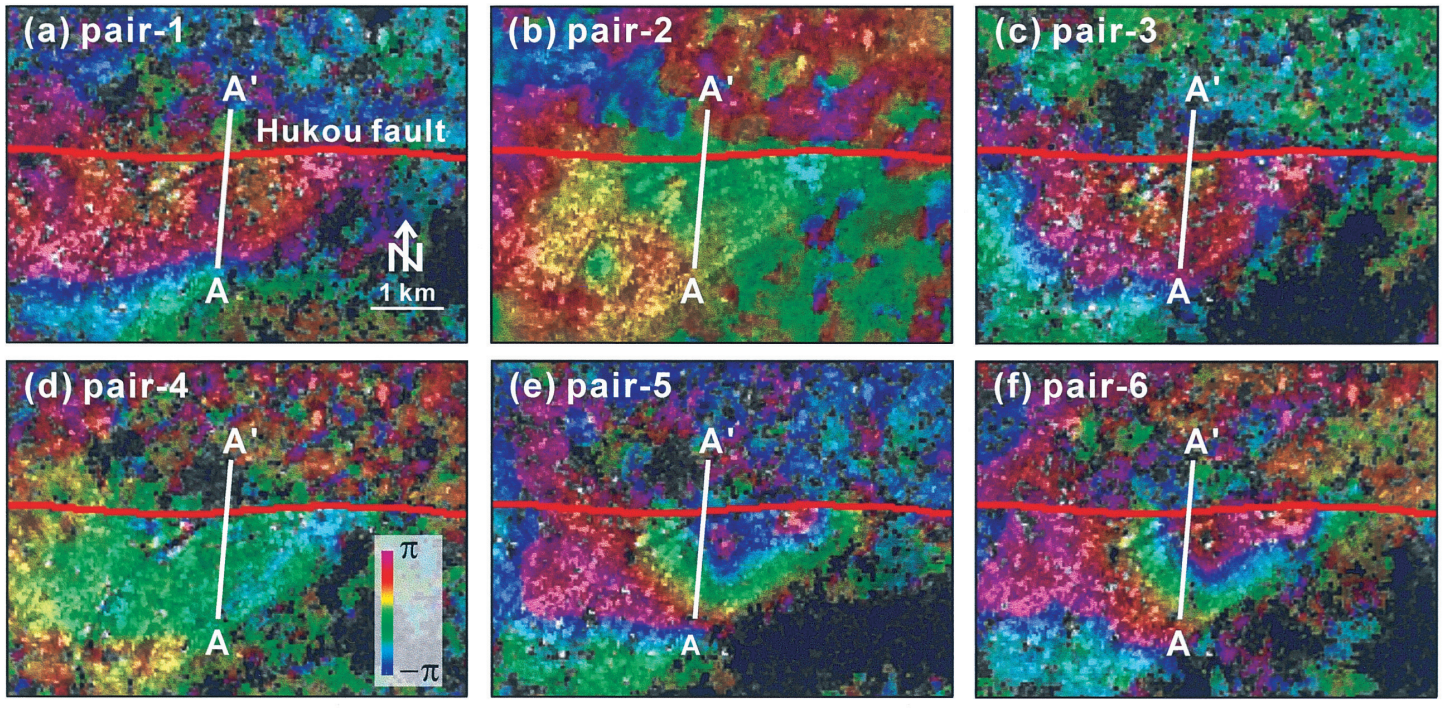

Fig. 7. Interferograms of the Hukou area. (a) Pair-1: 1993/11/10 1995/6/16 (year/month/day); (b) Pair-2: 1996/1/12 2000/1/22; (c) Pair-3: 1997/2/ $1 \sim$ 1999/7/31; (d) Pair-4: 1998/3/28 2000/1/22; (e) Pair-5: 2000/1/22 2003/2/15; (f) Pair-6: 2000/8/19 2003/2/15.

et al. 2004b). We chose six image pairs recorded in the last ten years for determining this land subsidence in detail. In Fig. 9, interferometric results reveal several circular-shape subsidences, the most conspicuous one is situated within the center of the Chungli Industry Park. Quantitative analysis clearly shows that this subsidence event occurred from 1996, reached its maximum rate (larger than $1 \mathrm{~cm} \mathrm{yr}^{-1}$ ) around 1999, and ended after 2000 (Figs. 10a, b and c). The rapid change in subsidence rate and the circular-shape of subsidence distribution illustrate that these are human-caused influences. For example, groundwater pumping may be an important factor in land subsidence in the Chungli area. In fact, about $20 \%$ factories in the Chungli Industry Park belong to the steel industry; these factories pump a considerable amount of groundwater for cooling. Field investigation show that many factories have moved out since 2000, which coincides with the time the land subsidence ceased.

In this case, the radar interferometry technique successfully observed the deformation when no other geodetic survey has been set up in this region. The high rate of land subsidence of the Chungli area has attracted our attention in the possible application of radar interferometry technique to monitor crustal deformation in areas that have high potential for environmental hazard. This case clearly suggests that this technique can monitor minute change caused by human activity and help mitigate environment hazards. 
(a) slant range displacement
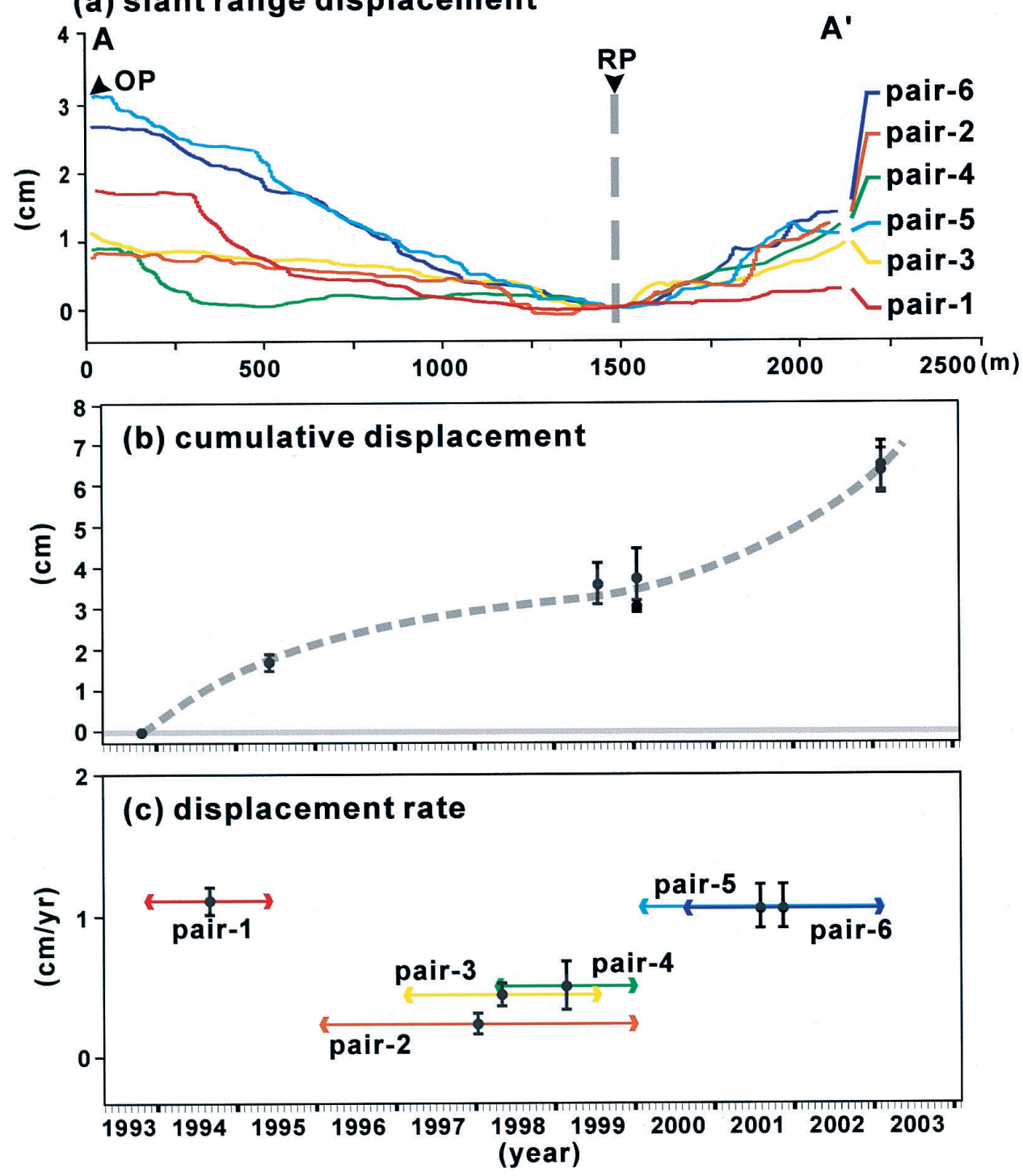

Fig. 8. (a) Slant range displacement along the profile AA' in Fig. 7. OP: observing point; RP: reference point. (b) Estimated cumulative displacement between $\mathbf{O P}$ and RP in Figure a. Explication of error bar in Figure 6. (c) Displacement rate between the $\mathbf{O P}$ and $\mathbf{R P}$ of each image pair in Fig. 8a. 

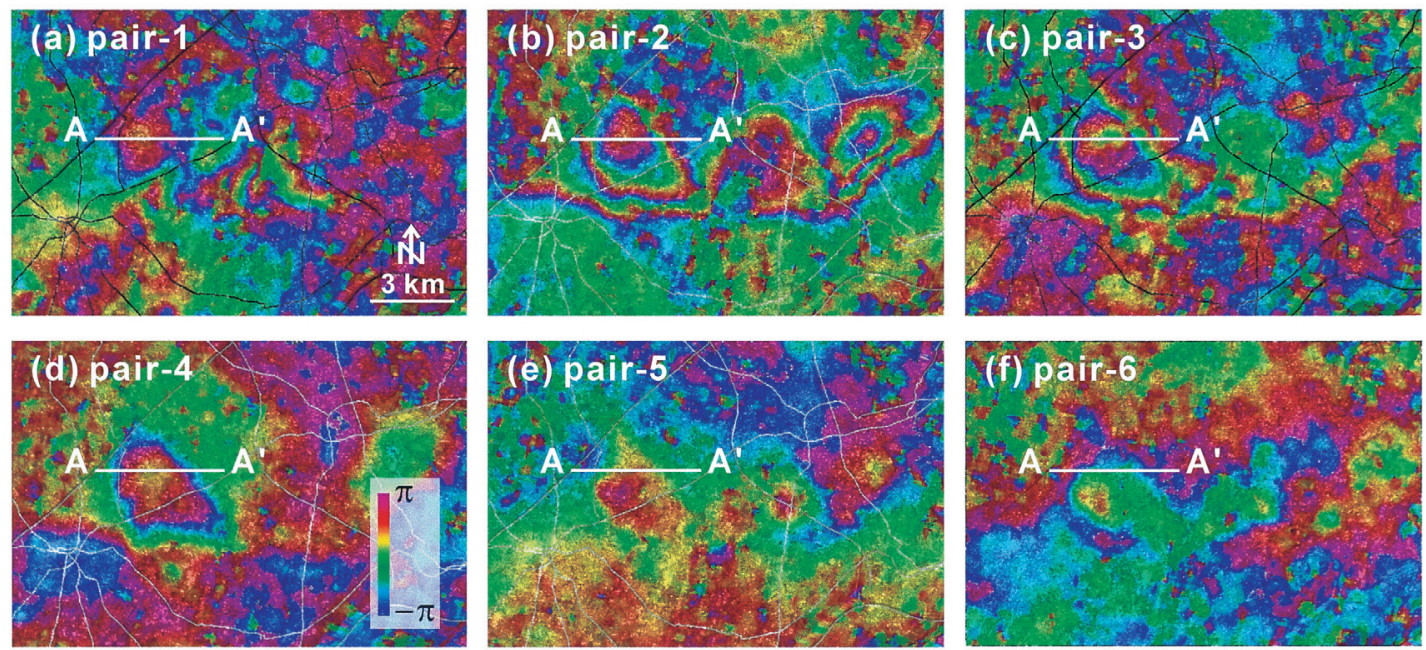

Fig. 9. Interferograms of the Chungli area. (a) Pair-1: 1993/11/10 1995/6/16 (year/month/day); (b) Pair-2: 1996/1/12 2000/1/22; (c) Pair-3: 1997/2/ $1 \sim$ 1999/7/31; (d) Pair-4: 1998/3/28 2000/1/22; (e) Pair-5: 2000/1/22 2003/2/15; (f) Pair-6: 2000/8/19 2003/2/15.

Pingtung area:

Another case related to human activity is deformation that occurred in the Pingtung plain of southern Taiwan. The Pingtung plain is elongate in shape with an area of $1210 \mathrm{~km}^{2}$, roughly $55 \mathrm{~km}$ in length and $20 \mathrm{~km}$ in width (see Fig. 12a). The highest elevation point on this plain is $80 \mathrm{~m}$ above the mean sea level, located in its northeastern most corner, which means the plain dips on a very gentle gradient to the southwest. The entire Pingtung plain is composed of fluvial gravel and sand in the top several tens of meters. In general, grain size decreases from east to west as well as from north to south.

The most distinctive hydrological character in the Pingtung plain is the alternation of dry/ wet seasons. Continuous daily rainfall records from November 1995 to June 1999 (data after the Central Weather Bureau) show that more than $90 \%$ of precipitation falls in the wet season either from typhoons or the summer monsoon from May to October. In contrast, the dry season, from November to March gives only about $10 \%$ of annual rainfall. Over the last few years, it has been observed that the rate of land subsidence is quite fast on the Pingtung plain (Chang et al. 2004c; Hou et al. 1997, 1998). Moreover, the subsidence rates vary very greatly between seasons. There is a considerable correlation between seasonal groundwater discharge and landsurface deformation.

The resultant differential interferograms of different image pairs are shown in Fig. 11. In this figure, the interferograms d1, d2, and d3 correspond to the dry seasons in 1996, 1997, and 
(a) slant range displacement
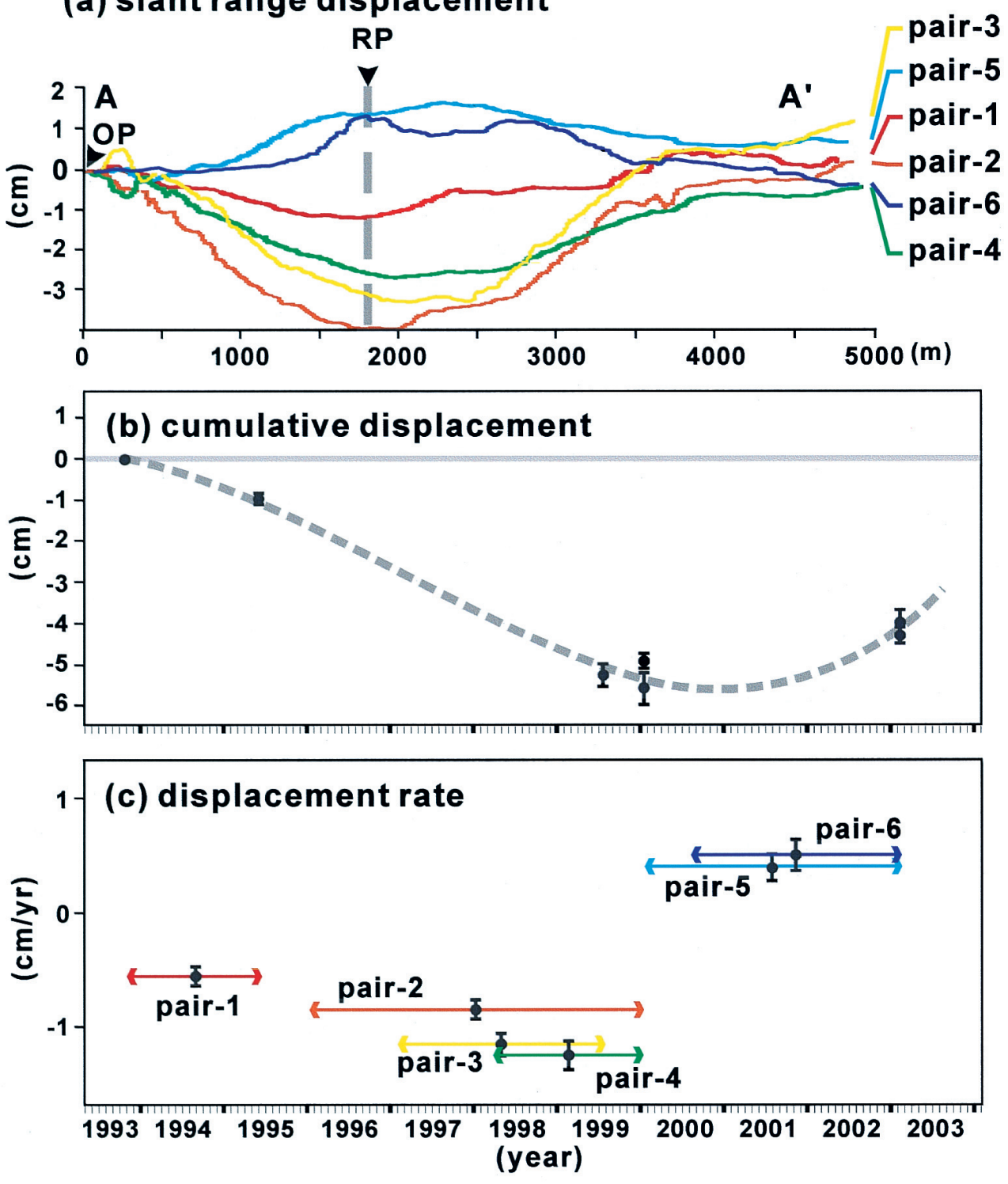

Fig. 10. (a) Slant range displacement along the profile AA' in Fig. 9. OP: observing point; RP: reference point. (b) Estimated cumulative displacement between $\mathbf{O P}$ and RP in Fig. a. Explication of error bar in Figure 6. (c) Displacement rate between the $\mathbf{O P}$ and $\mathbf{R P}$ of each image pairs in Fig. 10a. 

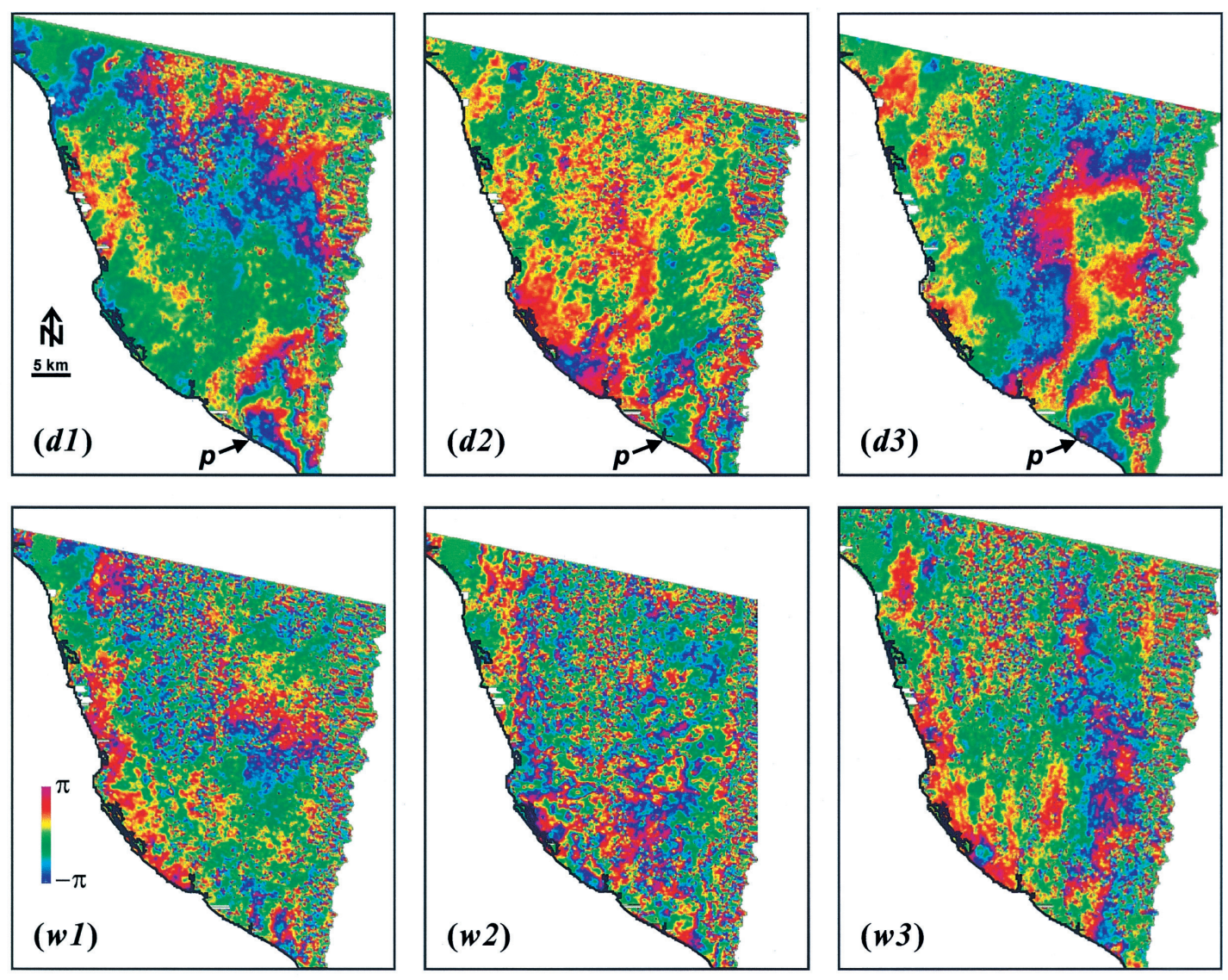

Fig. 11. Interferograms of the Pingtung area. Interferograms $\mathrm{d} 1 \sim 3$ are for the dry season; w1 $\sim 3$ are for the dry season. Time intervals of the interferograms: d1: 1996/1/31 1996/5/16 (year/month/day); d2: 1996/ 12/12 1997/5/1; d3: 1998/11/12 1999/5/6; w1: 1996/6/20 1996/10/ 3; w2: 1997/5/1 1997/9/18; w3: 1998/7/30 1998/11/12. P: descending center of the region.

1999; the interferograms of w1, w2, and w3 indicate the results of the wet seasons in 1996, 1997, and late 1998. We also found interferometric fringes are more distinct in the dry seasons, especially in the distal (southeastern) part of the Pingtung plain (Figs. 11 and 12). However, interferometric correlation is poor for the wet seasons, when it is difficult to distinguish a significant fringe representing the deformation signal. As a summary, the maximum subsidence rate achieves $3-6 \mathrm{~cm}$ per year at the distal part of the Pingtung plain, while this displacement mainly occurs in the dry season. During the wet season, the deformation rate is much lower. 
Land subsidence on a local rather than a regional scale is frequently caused by the dewatering of sediments. We thus consider groundwater level fluctuations in this area as a factor for differential land subsidence. The daily records of groundwater level from seven representative wells are compiled and shown in Fig. 12b (data after the Central Geological Survey). The time periods of the six InSAR pairs corresponding to dry and wet seasons are also marked in this figure in light and dense shadows, respectively. It is shown that when the land subsidence is significant, in the dry seasons, the water table is dropping, while the water table is rising when the land subsidence is minor in the wet seasons. As we know, the aqua-farmers in this area pump more water for farming during the dry season. We consequently infer that land subsidence occurring on the Pingtung plain is the result of dewatering that removes buoyant support for the sediments.

\section{CONCLUSIONS AND PERSPECTIVES}

In the case of intense events (Section 3.1), concentric fringe patterns are clearly shown in the footwall area of the Chi-Chi earthquake; these fringes indicate co-seismic displacement in
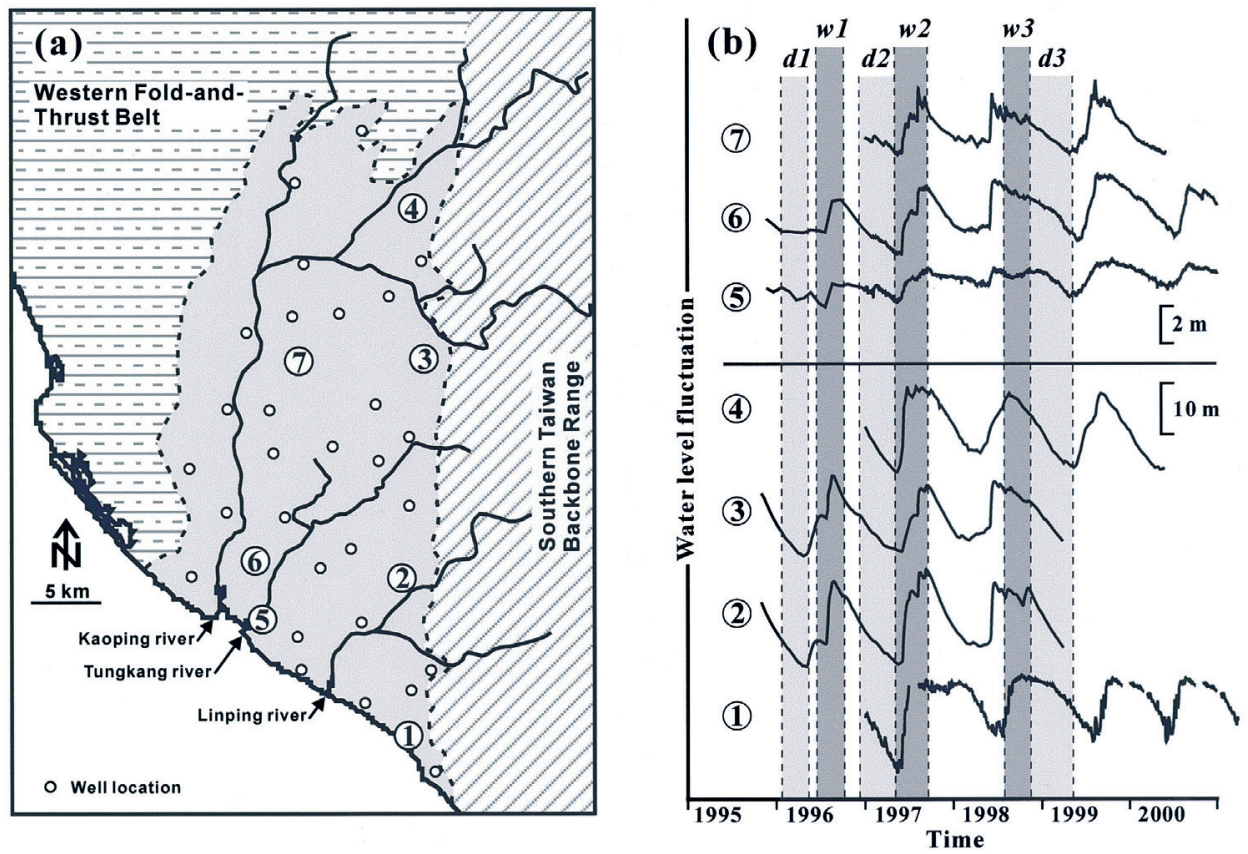

Fig. 12. (a) Groundwater Monitoring Network in the Pingtung plain established by the Central Geological Survey of Taiwan. (b) Groundwater level fluctuations of the Pingtung plain. Time intervals of the interferograms of Fig. $11(\mathrm{~d} 1 \sim 3$ and $\mathrm{w} 1 \sim 3)$ are also shown. 
the Taichung area. In gentle event cases, the Tainan tableland area shows a continuous uplift compared to the area surrounding it, and had a reverse tilting movement possibly caused by the occurrence of the Chi-Chi earthquake. In the Hukou area, there are two distinctive deformation patterns across the Hukou fault. The hanging wall of the Hukou fault is moving northward while the frontal edge of the hanging wall is uplifting slower than the back part of the hanging wall. The subsidence rates of the Chungli and Pingtung areas change very rapidly, and we conclude that these subsidence events are all induced by water pumping activity due to the correlation between our interferometric results and water table records.

The application of radar interferometry presented in this study shows that, with suitable images, this technique is a useful high-resolution tool for monitoring different types of crustal deformation in spite of the difficulties proposed due to dense subtropical vegetation in an area such as Taiwan. In a rather flat study area, where the major land uses are urban or a mixture of non-vegetated and vegetated land, it is proven that interferograms obtained by C-band radar can bring reasonable displacement information. However, poor results in the mountainous area suggested a limitation of C-band radar in steep regions with dense vegetation.

It is worth mentioning that uncertainties in coherence, signal/noise ratio, unwrapping error and residual fringes from DEM lower the precision of interferometric results. For intense events that generally yield large deformations within a short time, we can use corresponding geodetic data from GPS networks to improve our interferometric results (e.g., the case of Chi-Chi earthquake). However, for gentle events that do not have a single catastrophic incident but are due to effects spread over time with smaller and probably continuous incidents, the resultant interferograms come with more uncertainties. Two approaches can be used to solve this problem: the first is application of permanent GPS stations, which can calibrate interferometric results; the second is to promote frequency of image acquisition. However, these two approaches consume large amounts of resources making such goals more difficult to achieve. In this paper we tried to choose precise orbit parameters and image calibrations during the interferometry processes. In cases that used image pairs with a high altitude of ambiguity, the interferometric results are typically more precise (see examples of Figs. 5, 7 and 9).

According to the cases presented in this paper, areas with high deformation rates are all next to highly populated areas or industrial parks. Implications here being that to mitigate potential hazards continuous monitoring and further study of neo-tectonic and human activities are urgently needed. We believe that geological applications for radar interferometry will continue to grow rapidly. As the examples presented in this paper indicate radar interferograms are a valid method for surface deformation measurement. The results come with unprecedented spatial density and compare favorably with other measurements, theoretical models, and engineering expectations. In short, the precision of the technique is now sufficiently high that many new and exciting geophysical applications are already within reach.

Acknowledgements This work was supported by the Ministry of Education (grant no. 91-NFA07-7-4), National Science Council (grant no. NSC92-2119-M-008-016) and Central Geological Survey (grant no. 5226902000 -03-93-04). The full discussions with Drs. Y. B. Tsai, K. F. Ma, H. Y. Yen, J. Y. Liu, and Y. I. Chen have been very helpful. The authors are deeply indebted to two anonymous reviewers for their helpful comments. 


\section{REFERENCES}

Barrier, E., and J. Angelier, 1986: Active collision in eastern Taiwan: the Coastal Range. Tectonophys., 125, 39-72.

Biq, C., 1973: Kinematic pattern of Taiwan as an example of actual continent-arc collision. Report of the Seminar on Seismology. US-ROC Coop. Sci. Prog., 25, 149-166.

Bowin, C., R. S. Lu, C. S. Lee, and H. Schouten, 1978: Plate convergence and accretion in Taiwan-Luzon region. Am. Assoc. Petr. Geol. Bull., 62, 1643-1672.

Burgmann, R., P. A. Rosen, and E. J. Fielding, 2000: Synthetic aperture radar interferometry to measure Earth's surface topography and its deformation. Ann. Rev. Earth Planet. Sci., 28, 169-209.

Burgmann, R., M. E. Ayhan, E. J. Fielding, T. J. Wright, S. McClusky, B. Aktug, C. Demir, O. Lenk, and A. Turkezer, 2002: Deformation during the 12 November 1999 Duzce, Turkey, earthquake, from GPS and InSAR data. Bull. Seism. Soc. Am., 92, 161-171.

Chai, B. H. T., 1972: Structure and tectonic evolution of Taiwan. Am. J. Sci., 272, 389-422.

Chang, C. P., T. Y. Chang, J. Angelier, H. Kao, J. C. Lee, and S. B. Yu, 2003: Strain and stress field in Taiwan oblique convergent system: Constraints from GPS observations and tectonic data. Earth Planet. Sci. Lett., 214, 115-127.

Chang C. P., C. T. Wang, T. Y. Chang, K. S. Chen, L. S. Liang, E. Pathier, and J. Angelier, 2004a: Application of SAR interferometry to a large thrusting deformation: The 1999 $M_{w}=7.6$ Chi-Chi earthquake (Central Taiwan). Geophys. J. Inter., 158 (in press).

Chang, C. P., C. T. Wang, H. C. Wang and K. S. Chen, 2004b: Application of DInSAR in monitoring the metropolitan land-surface deformation: Jungli industry park as an example. J. of Photogrammetry and Remote Sensing, 9, 9-14.

Chang, C. P., T. Y. Chang, C. T. Wang, C. H. Kuo, and K. S. Chen, 2004c: Land-surface deformation corresponding to seasonal ground-water fluctuation, determining by SAR interferometry in the SW Taiwan. Math. Comp. Simulation, 67 (in press).

Chang, H. C., C. W. Lin, M. M. Chan, and S. T. Lu, 1998: An Introduction to the Active Faults of Taiwan: Explanatory Text of the Active Fault. Central Geological Survey, 103p.(in Chinese with English abstract).

Delouis, B., D. Giardini, P. Lundgren, and J. Salichon, 2002: Joint inversion of InSAR, GPS, teleseismic, and strong-motion data for the spatial and temporal distribution of earthquake slip: Application to the 1999 Izmit mainshock. Bull. Seism. Soc. Am., 92, 278299.

Donnellan, A, J. W. Parker, and G. Peltzer, 2002. Combined GPS and InSAR models of postseismic deformation from the Northridge earthquake. Pure Appl. Geophys., 159, 2261-2270.

Feigl, K. L., F. Sarti, H. Vadon, S. McClusky, S. Ergintav, P. Durand, R. Burgmann, A. Rigo, D. Massonnet, and R. Reilinger, 2002: Estimating slip distribution for the Izmit mainshock from coseismic GPS, ERS-1, RADARSAT, and SPOT measurements. Bull. Seism. Soc. Am., 92, 138-160.

Hou, J. H., D. J. Lia, and L. Y. Fei, 1997: Application of GPS in monitoring the land-subsidence of the Pingtung plain. Annual meeting, Geol. Soc. China, Taiwan, 55-58. 
Hou, J. H., L. Y. Fei, and D. J. Lia, 1998: GPS investigation in the Pingtung plain. Conference of Groundwater and Hydrogeology, Taiwan, 239-252.

Hudnut, K. W., Y. Bock, M. Cline, P. Fang, Y. Feng, J. Freymueller, X. Ge, K. Gross, D. Jackson, M. Kim, N. King, J. Langbein, S. Larsen, M. Lisowski, Z. Shen, J. Svarc, and J. Zhang, 1994: Coseismic displacement of the 1992 Landers earthquake sequence. Bull. Seis. Soc. Am., 84, 625-645.

Lee, J. C., Y. G. Chen, K. Sieh, K. Mueller, W. S. Chen, H. C. Chu, Y. C. Chan, C. Rubin, and R. Yeats, 2001: A vertical exposure of the 1999 surface rupture of the Chelungpu fault at Wufeng, western Taiwan: Structural and paleoseismic implications for an active thrust fault. Bull. Seis. Soc. Am., 91, 914-929.

Ma, K. F., T. R. A. Song, S. J. Lee, and H. I. Wu, 2000: Spatial slip distribution of the September 20, 1999, Chi-Chi, Taiwan, earthquake ( $M w$ 7.6) - Inverted from Teleseismic data. Geophys. Res. Lett., 27, 3417-3420.

Massonnet, D., M. Rossi, C. Carmona, F. Adragna, G. Peltzer, K. Feigl, and T. Rabaute, 1993: The displacement field of the Landers earthquake mapped by radar interferometry. Nature, 364, 138-142.

Massonnet, D., and K. L. Feil, 1998: Radar interferometry and its application to changes in the Earth's surface. Rev. Geophys., 36, 441-500.

Pathier, E., B. Fruneau, B. Deffontaines, J. Angelier, C. P. Chang, S. B. Yu, and C. T. Lee, 2003 : Coseismic displacements of the footwall of Chelungpu fault by the 1999, Taiwan, Chi-Chi earthquake from InSAR and GPS data. Earth Planet. Sci. Lett., 212, 73-88.

Rubin, C., K. Sieh, Y. G. Chen, J. C. Lee, H. C. Chu, R. Yeats, K. Mueller, and Y. C. Chan, 2001: Post-earthquake response, 1999 Chi-Chi earthquake: evidence for past earthquakes. Eos, Trans Am. Geophys. Uion, 82, 47, 565.

Sun, S.C., 1964: Photogeologic study of the Tainan-Kaohsiung coastal plain area, Taiwan. Petrol. Geol. Taiwan, 3, 39-51.

Suppe, J., 1981: Mechanics of mountain building and metamorphism in Taiwan. Mem. Geol. Soc. China, 4, 67-89.

Suppe, J., 1984: Kinematics of arc-continent collision, flipping of subduction and back-arc spreading near Taiwan. Mem. Geol. Soc. China, 6, 21-34.

Tang, C. H., 1963: Geology and Oil Potentialities of the Hukou Anticline, Hsinchu.Petrol. Geol. Taiwan, 2, 241-252.

Teng, L. S., 1990: Geotectonic evolution of Late Cenozoic arc-continental collision in Taiwan. Tectonophys., 183, 57-76.

Teng, T. L., Y. B. Tsai, and W. H. K. Lee, 2001: Special Issue of the Taiwan Earthquake, Preface to the 1999 Chi-Chi, Taiwan, Earthquake dedicated issue. Bull. Seism. Soc. Am., 91, 1395 pp.

Tsai, Y. B., 1986: Seismotectonics of Taiwan. Tectonophysics, 125, 17-37.

Yu, S.B., H. Y. Chen, and L. C. Kuo, 1997: Velocity field of GPS stations in the Taiwan area. Tectonophys., 274, 41-59. 
Yu, S. B., L. C. Kuo, Y. J. Hsu, H. H. Su, C. C. Liu, C. S. Hou, J. F. Lee, T. C. Lai, C. C. Liu, C. L. Liu, T. F. Tseng, C. S. Tsai, and T. C. Shin, 2001: Preseismic deformation and coseismic displacements associated with the 1999 Chi-Chi, Taiwan, Earthquake. Bull. Seis. Soc. Am., 91, 995-1012.

Zebker, H. A., P. A. Rosen, R. M. Goldstein, A. Gabriel, and C. L. Werner, 1994: On the derivation of coseismic displacement fields using differential radar interferometry: The Landers earthquake. J. Geophys. Res., 99, 19617-19634. 